\title{
The Focus of Quality Management Practices: A National Culture Perspective
}

\author{
Dongli Zhang ${ }^{1} \&$ Sarah Jinhui $\mathrm{Wu}^{1}$ \\ ${ }^{1}$ Gabelli School of Business, Fordham University, U.S.A \\ Correspondence: Dongli Zhang, Gabelli School of Business, Fordham University, 441 East Fordham Rd, Hughes \\ Hall 510, Bronx, NY 10458, U.S.A. Tel: 1-718-817-4145. E-mail: dzhang@fordham.edu
}

Received: September 16, 2013

Accepted: December 20, 2013 Online Published: January 20, 2014

doi:10.5539/ijbm.v9n2p91

URL: http://dx.doi.org/10.5539/ijbm.v9n2p91

\begin{abstract}
The effectiveness of quality management practices under different national culture environments is investigated in this study. We bundle quality management practices by two orientations based on learning theoryand then investigate if any type of quality management practices shows stronger relationship with performance within different national culture environments. The hypotheses were tested using a survey dataset witha sample size of 238 which were collected from eight countries. Data analysis results show that exploitative quality practices are highly related to performance outcome in national cultures featured by high power distance and high uncertainty avoidance. In contrast, exploratory quality practices are significantly associated with operations performance in nations with low power distance and low uncertainty avoidance. The study suggests that quality management practices be adopted selectively based on the national culture profile. It advances our understanding of quality management practices from the context dependent perspective and provides guidelines for practitioners onimplementing quality practices successfully in different cultural environments.
\end{abstract}

Keywords: quality management, national culture, power distance, uncertainty avoidance

\section{Introduction}

In the fast changing business world, organizations continuously search for new ways to improve performance and gain competitive advantages. Quality Management (QM) has been widely used in many nations with the expectation of helping organizations improve performance. Yet, the inconsistent performance results from those QM practices still trouble both scholars and practitioners. How to get the maximum benefits from implementing QM practices is a critical question for both practitioners and researchers that needs to be answered.

Reviewing the literature of $\mathrm{QM}$, scholars have been trying to answer this question from different perspectives. One perspective focuses on the "hard" aspect of QM practices such as practices, techniques, tools, and systems. The other perspective recognizes the implications of the "soft" behavioral and cultural aspects of QM. These behavioral and cultural aspects of QM are relatively more difficult to measure and change compared to the technical aspect of QM. National culture, a potential factor which might influence the effectiveness of QM practices, was mentioned in several recent studies (e.g., Naor et al., 2010; Kull \&Wacker, 2010). Some of the studies proposed that many QM failures resulted from the ignorance of different national culture settings (Flynn \& Saladin, 2006; Kull \& Wacker, 2010; Zhao et al., 2007). Therefore, multi-country and cross-cultural research shows a growing need in the field of quality management.

Our study echoes this need by assessing the effectiveness of QM practices on a sample of eight countries with dramatically different culture profiles. We adopt Zhang et al. (2012) approach of classifying QM practices into a type that focuses on exploitation and another type that encourages exploration. Exploitative QM practices emphasize more on the process control and variance reduction whereas exploratory QM practices underscore more on the searching for new methods, new approaches, and new solutions. We believe that these two types of activities may require different supporting value systems. We use the Hofstede's framework of national culture but focus on two critical dimensions which are morerelevant to working environment-power distance and uncertainty avoidance-to classify the countries into two groups. We then empirically investigate the performance influences of the two bundles of QM practiceswithin the two cultural groups.

This study enriches the literature of quality management from a national cultural perspective, offers a newlens 
of implementing quality practices in different cultural environments. It advances our understanding of quality management practices from the context dependent perspective. Particularly, the study suggests that quality management practices be adopted selectively based on the national culture profile. Quality managers need to allocate limited resources to make QM practices contribute more to performance, and the results of this study will provide them a useful guideline on the resource allocation.

Following this introduction section, relevant literatures are reviewed in the next section and hypotheses are developed accordingly. Section 3 presents the data andthe measurement instruments. Data analysis and the major results are reported in Section 4, followed by discussion and implications in Section 5. The last section concludes the study.

\section{Literature and Hypotheses}

We begin with a general discussion of the potential impact of national culture on quality management. Then we review literature that differentiates QM practices into two types with different orientations: exploitation and exploration. Hofstede's national culture framework is discussed afterwards. Lastly, grounded upon the contingency perspective, we develop hypotheses, statingthat certain quality management practices could better improve operations performance if they are aligned with the certain national culture features.

\subsection{Impact of National Culture on Quality Management Practices}

Previous research showed that without certain modifications, management theories cannot often be effectively implemented when they spread across different nations. The main reason of this is that there existes attitudinal and behavioral differences between different nations (Lytle et al., 1995). The culture of the environment within which an organization operates affects the management practices and processes (Hofstede, 1994b). Therefore, management practices must be tailored to fit any specific environmental settings.

While the influence of organizational culture and quality culture on the effectiveness of QM practices has been well studied and assessedin the literature (Bates et al., 1995; Bright \& Cooper, 1993; Naor et al., 2008; Powell, 1995), the importance of a country's national culture to QM has not. A nation's culture is defined as "shared motives, values, beliefs, identities, and interpretations or meanings of significant events that result from common experiences of members of collectives that are transmitted across generations" (House et al., 2004).National culture influences organizational behavior at such a deep level that sometime it is hard for people to be aware of it, and therefore most of the time people fail to take it into account (Triandis, 1983). However, national culture can be critical in influencing the success or failure of certain management practices. For instance, in Flynn and Saladin (2006) study, Hofstede's national culture dimensions are found to be related to performance on almost all QM practices under Baldrige framework. The only exception is customer and market focus. In another multi-country study, Lagrosen (2003) found that across 30 countries, there exist significant correlations among a set of QM practices and Hofstede's culture dimensions. National cultural profile may not affect quality performance directly, argued by Lozeau et al. (2002), however, it could generate an environment which may have impact on whethercertain QM practices will be more effective or less.

This study builds upon this line of research and further assesses what kind of QM practices is more effective in improving overall operations performance under different national cultural settings through the lens of contingency theory. The literature on quality management has already adopted the contingency perspectivewhich recognizes the need to attune/customize QM practices to certain contextual requirements. Some QM practices and tools work better under certain situations while others might be inappropriate in the same situation (Dean \& Bowen, 1994; Sitkin et al., 1994). Therefore, adopting the right set of QM practices will bring more benefit to an organization. The contingency view of quality management has gained its attention during the past few years, and many studies have identified the contingent factors and evaluated their influences on practice effectiveness (e.g., Zhang et al., 2012; Sousa \& Voss, 2008; Foster, 2006). More importantly, how to customize the content of the quality practices based on different contextual settings needs to be investigated more intensely (Foster, 2006; Sousa \& Voss, 2008).

Categorizing quality practices into different orientations provides the foundation for customizing the contents. There are different approaches to categorize quality management practices. For example, in (Dow et al., 1999), quality practices are grouped into process related practices and people related practice. In some other studies, quality practices are categorized into another two different groups: core practices and infrastructure practices (Cua et al., 2001; Flynn et al., 1995; Naor et al., 2008). We follow the framework of Zhang et al. (2012) in this study and classify QM practices into explorativeand exploitative practices that is grounded upon March's (1991) framework of learning since QM is essentially a continuous improvement program with learning as the core. 
Organizations face two tasks: control stable process and improve efficiency, and search for new insights for innovation. As such, exploitative QM practices are needed to control the known processes, while exploratory QM practices are needed to explore the unknown and search for novel solutions (Wu et al., 2011; Zhang et al., 2012). Selection of the appropriate quality management practices to use may rely on many factors, which can be internal and external factors. National culture, one of the critical external factors, is the focus of this study.

\subsection{Hypotheses Development}

To capture the big picture of a nation's culture, Hofstede (1980) identified four dimensions (power distance, uncertainty avoidance, individualism/collectivism, and masculinity/femininity). In his later work, long-term orientation was added on the framework as the fifth dimension. Table 1 gives the summary of the five dimensions and their definitions. Among the five dimensions, he pointed out that the most critical dimensions that affect the management practices in working environment are power distance and uncertainty avoidance (1994a, 1994b, 1997). Flynn and Saladin (2006) also provided the same argument. Therefore, in this study we focus more attention on these two dimensions. Comparing to the other three dimensions, these twomighthave more influence on QM effectiveness.

Table 1. Five national culture dimensions

\begin{tabular}{|c|c|}
\hline Dimension & Definition \\
\hline Power distance & $\begin{array}{l}\text { Extent to which members with less power in organizations within a certain nation hope that power to be } \\
\text { distributed equally }\end{array}$ \\
\hline $\begin{array}{l}\text { Uncertainty } \\
\text { avoidance }\end{array}$ & Degree to which members are uncomfortable because of situations they feel to be unpredictable or unstructured \\
\hline Individualism & Degree to which people in a certain nation tend to acting as individuals versus acting as a part of a group \\
\hline Masculinity & Extent to which success and aggressiveness are valued, instead of concerning for relationships \\
\hline $\begin{array}{l}\text { Long-term } \\
\text { orientation }\end{array}$ & Time perspective and an attitude of overcoming obstacles or persevering with time \\
\hline
\end{tabular}

Hofstede (1980) defines power distance as an extent to which members with less power of organizations in a certain nation hope that power to be distributed equally. QM programs require employee involvement, which encourages employees to bring up ideas and suggestions for quality improvement (Zhang et al., 2012). Tata and Prasad (1998) specifically state that for the purpose of implementing QM, Hofstede's construct of a high power distance index creates a difficult and unfriendly environment. Members in high power distance countries tend not to disagree with their superiors. In order to relieve their own responsibility, employees hope their superiors show paternalistic behaviors. Under this type of high power distance culture, it would be relatively easier to implement exploitative-oriented practices since they require following ordersand improving efficiency. When organizations operate in a culture with lower power distance, which emphasizing and fostering open communications between different levels, it would be relatively easier to make teamwork more effective. It could also leads to empowerment of the employees. Under this type of low power distance culture, employees will be more encouraged to come up with innovative ideas, provide constructive suggestions, and make independent decisions. Regardless of their hierarchical level in the organization, employees feel freer to express their own ideas and thoughts. Therefore, this type of low power distance culture is more supportivefor explorative QM practices.

Uncertainty avoidance is defined as a degree (Hofstede, 1980) to which people within a culture are uncomfortable by situations they feel to be unpredictable, unstructured, or unclear. This dimension deals with a society's tolerance for uncertainty and ambiguity, and it shows to what extent members in a certain culture are programmed to feel either uncomfortable or comfortable in unstructured situations that are novel, unknown, surprising, and different from usual. In order to alleviate such kind of unfamiliar situations, cultures featured with high uncertainty avoidance tend to rely on norms and procedures (House et al., 2004). Employees within such kind of culture are more likely to follow standard procedures very closely. They also try to listen to customer feedbackintentlyand make necessary changes in orderly ways. Thus, culture featured with high uncertainty avoidance is more associated with standard systems, formal process controls, and reliance on experts. These features are congruent with the value under exploitative-oriented practices. For instance, Kull and Wacker (2010) found that uncertainty avoidance significantly increases the effectiveness of certain quality practices. Operating in a culture which is threatened by unpredictability, organizationstend to implement more practices 
that focus on process control and standardization, for example, ISO 9000. In contrast, employees from low uncertainty avoidance cultures are more willing to deal with unknown or different situations. They do not worry that much about making mistakes and, therefore, feel more comfortable to explore and try alternative solutions. Such kinds of cultural elements spawn innovations and make explorative-oriented quality practices easy to take place.

Overall, when the national culture is featured with high power distance and high uncertainty avoidance, exploitative QM practices would be better supported since this kind of culture encourages obeying rules and following existing procedures. In contrast, a national culture featured with low power distance and low uncertainty avoidance provides a more relaxing environment for employees to express creative ideas and try out innovative solutions. This type of culture will promote the effectiveness of exploratory QM practices. As such, we propose the following hypotheses that reflect the relationships between the different QM practices and operational performance within different cultural groups.

H1. Exploitative quality management practices positively affect overall operations performance more than exploratory quality management practices in the nationswhose culture is featured with high power distance and high uncertainty avoidance.

H2. Exploratory quality management practices positively affect overall operations performance more than exploitative management quality practicesin the nations whose culture is featured with low power distance and low uncertainty avoidance.

\section{Research Method}

\subsection{Data Collection}

The data to test the hypotheses come from the third round of High Performance Manufacturing (HPM) project using survey method. The data consists of plants from three industries (Automotive, Electronics, and Machinery) and eight countries (Austria, Finland, Germany, Italy, Japan, Korea, Sweden, and the United States).Scholars from different countries contacted 366 plantsrandomly selected from a master list either by personal visit or telephone. The research group also promised to provide each participating plant a summary report which could help plants benchmark. With all the above effect, the project resulted with a final sample size of 238 which represents a response rate of $65 \%$. The data are relatively evenly distributed across industries and countries. The sample plants also have size requirement, which ensured all the plants have at least 250 employees.

In order to improve reliability of the data and reduce possible common methods bias, the survey used multiple respondents in each plant and also multiple measurement methods (e.g. subjective and objective).The survey was divided into 13 sets of questionnaires. Managers, supervisors, and production workers are all participated in the survey. Most questions have been answered by multiple respondents. For instance, quality practice questions have an average of 8 respondents and were answered by quality managers, supervisors, andworkers. Multiple responses from each plant were finally aggregated to the plant level and the final sample consists of 238 plants with one aggregated response per plant.

\subsection{Measures}

\subsubsection{Exploitative and Exploratory Quality Practices}

We adopted the measurement instrument of exploitative and exploratory QM practices from Zhang et al. (2012). Their measurement instrument (Appendix) has been empirically validated and shown satisfactory psychometric properties (the factor loadings from confirmatory factor analysis and the model fit indices are summarized in Figure 1). Exploitative and exploratory QM practices were modeled as second-order latent factors measured through the four first-order factors that cover the commonly used dimensions of QM practices-customer focus, process management, teamwork, and training. The second-order factor model shows good fit of the data. All the factor loadings are significant at $\mathrm{p}<0.01$. The model has a Root Mean Square Error of Approximation (RMSEA) of 0.059 , NNFI of 0.91 , CFI of 0.92 , and IFI of 0.92. $\chi 2$ /degree of freedomhas a value of 1.83 , which is lower than the recommended value of 2 .

\subsubsection{Operations Performance}

The overall operational performance was used in the model as the dependent variable. This dependent variable will help us evaluate the effectiveness of different types of QM practices.Itcaptures and summates four dimensions of performance-cost, quality, delivery, and flexibility. The measurement items for the four dimensions of operational performance in this study, summarized in Table 2, were adapted from previous research (Cua et al., 2001; Narasimhan et al., 2006; Peng et al., 2008; Schroeder et al., 2002). 
Table 2. Measurement of operations performance

\begin{tabular}{ll}
\hline Performance dimension & Measurement \\
\hline Cost & Unit cost of manufacturing \\
& Inventory turnover \\
& Cycle time \\
Quality & Conformance to product specifications \\
& Product capability and performance \\
Delivery & On time delivery \\
& Fast delivery \\
Flexibility & Change product mix \\
& Change volume \\
\hline
\end{tabular}

Please check the number which shows your opinion about how your plant compares to its competitorson a global basis in your industry (1-Poor or low end of the industry, 3-Average, 5-Superior or better comparing to average).

\subsubsection{National Culture}

Hofstede'snational culture index scores were used to describe cultural environments of the eight countries where the manufacturing plants reside. Table 3 shows the culture index scores of the eight nations and the world average score of each dimension (Hofstede, 1997). All the index scores range between 0 and 100.

Table 3. National culture score for the eight countries

\begin{tabular}{llllll}
\hline Countries & Power & Individualism & Masculinity & $\begin{array}{l}\text { Uncertainty } \\
\text { avoidance }\end{array}$ & $\begin{array}{l}\text { Long } \\
\text { orientation }\end{array}$ \\
\hline Korea & $\mathbf{6 0}$ & 18 & & $\mathbf{8 5}$ & 75 \\
Japan & $\mathbf{5 4}$ & 46 & 39 & $\mathbf{9 2}$ & 80 \\
Italy & $\mathbf{5 0}$ & 76 & 95 & $\mathbf{7 5}$ & 34 \\
USA & $\mathbf{4 0}$ & 91 & 70 & $\mathbf{4 6}$ & 29 \\
Germany & $\mathbf{3 5}$ & 67 & 62 & $\mathbf{6 5}$ & 31 \\
Finland & $\mathbf{3 3}$ & 63 & 66 & $\mathbf{5 9}$ & 41 \\
Sweden & $\mathbf{3 1}$ & 71 & 26 & $\mathbf{2 9}$ & 20 \\
Austria & $\mathbf{1 1}$ & 55 & 5 & $\mathbf{7 0}$ & 31 \\
World Average & $\mathbf{5 2}$ & 40 & 48 & $\mathbf{6 1}$ & 44 \\
\hline
\end{tabular}

Source: http://geert-hofstede.com/countries.html

As discussed earlier, we focus on two of those dimensions particularly for the purpose of this study-power distance and uncertainty avoidance. The eight countries can be grouped into three cultural groups. Group one is featured with high power distance and high uncertainty avoidance. Two countries fall into this group: Japan and South Korea. Both of the nations have a power distance score and an uncertainty avoidance score much higher than the world average. The national culture of this group could be described as more Eastern. Group two includes Sweden, the U.S.A, and Finland. All the three countries have much lower score of both power distance and uncertainty avoidance than the world average. This group could be viewed as more western. Group three consists of the rest of the countries which have a mix of high/low power distance and low/high uncertainty avoidance where the impacts from each dimension are opposite to each other and the overall impacts of the two dimensions could cancel out each other. As such, we exclude them from further analysis.

\section{Data Analysis}

\subsection{Data Analysis Method}

Regression analysis was employed to assess the impacts of exploratory and exploitative QM practices on overall operations performance. The following regression model was repeated in each of the two groups with different cultural profile to see if the magnitude of exploratory and exploitative QM practices varies under different cultural environments. The regression model is formulated as:

Operations Performance $=\beta_{0}+\beta_{1}$ Industry $_{\text {Machinery }}+\beta_{2}$ Industry Electronics $+\beta_{3}$ Quality $_{\text {Exploitation }}+\beta_{4} \mathrm{Quality}_{\text {Exploration }}+\varepsilon$ 
Several control variables are considered in the regression model, for instance, industry, size of the plant, and age of the plant. However, neither of the size or the age of the plant showed significant relation with the operations performance. Therefore, only industry types were controlled in the regression model as dummy variables.

The analysis did not reveal any violations to the assumptions of linear regression model and ordinary least square method was employed to obtain the estimates for the regression coefficient.

\subsection{Major Analysis Results}

Table 4 reports the results of the regression analysis between the two cultural groups. In the Eastern group (group 1), exploitative QM practices showed a significant relationship with the overall operationsperformance (with a positive regression coefficient of 0.44 and p-value $<0.05$ ), whereasexploratory QM practices was insignificant. This results supported hypothesis 1 , which states that exploitative quality practicescontribute to performance more than exploratory QM practiceswithin the culture group of high power distance and high uncertainty avoidance. In contrast, in the western group (group 2), exploratory QM practicesturned out to besignificantly related with the overall operation performance (with a regression coefficient of 0.35 and p-value $<0.05$ ) while the regression coefficient of exploitative QM practiceswas insignificant. The results supported hypothesis 2, which expects a stronger effect fromexploratory QM practices when firms operating in a culture featuredwith low power distance and low uncertainty avoidance.

Both of the hypotheses were supported based on the data analysis results, which indicated that national culture is indeed an important contextual factor that influences the effectiveness of QM practices. Firms get more benefit from the QM practices that are congruent with the national culture systems in which they operate.

Table 4. Regression results in two cultural groups

\begin{tabular}{ccc}
\hline & \multicolumn{2}{c}{ Culture group } \\
\hline & $\begin{array}{c}\text { Eastern } \\
(\mathrm{n}=66)\end{array}$ & $\begin{array}{c}\text { Western } \\
(\mathrm{n}=83)\end{array}$ \\
\hline Industry $_{\text {Machinery }}$ & 0.01 & $0.27^{*}$ \\
Industry Electronics $_{\text {Quality }}$ & -0.14 & 0.02 \\
Qualititation & $0.44^{*}$ & -0.02 \\
R-Square & 0.03 & $0.35^{*}$ \\
$p$-value for the significance of the overall & 0.23 & 0.13 \\
model & $0.01^{*}$ & $0.04^{*}$ \\
\hline
\end{tabular}

Note: $* p<0.05$.

\subsection{Post-Hoc Analysis}

As national culture was found to bea key external factor that impacts the effectiveness of QM practices in Section 4.2, it would be more insightful to further explore if it intertwines with some internal factors and they simultaneously influence the effectiveness of QM practices. One of the internal factors is organizational structure that indicates the way that responsibility and power are allocated, and work procedures are carried out, among organizational members (Blau, 1970)

Organizational structure usually is identified with two typical forms: mechanistic structure versus organic structure (Daft, 2009). Daft (2009) also provides different aspects for differentiating different organizational structure,which might includestandardization, formalization, centralization, and hierarchy of authority. Limited by the data we have, this study focuses on the hierarchy dimension of organizational structure.

The number of layers in hierarchy measures the degreeto which an organization has many versus few levels of management (Burns \& Stalker, 1961; Germain et al., 2008). More levels in an organization typically indicate more formalization, standardization, and centralization; whereas fewer levels are usually related to a more open and flexible internal structure. Burns and Stalker (1961) state that organic organizations usually have few layers in their hierarchy and therefore have a relatively flat structure while mechanistic organizations usually have more layers and indicate a relatively more hierarchical structure. Therefore, in this study we use Hieratical and Flat to differentiate the firms based on their organizational structures.

In general, in a culture with high power distance and high uncertainty avoidance, members try not to disagreewith their superiors. To relieve their own responsibilities, they always hope that their superiors could 
show paternalistic behaviors. A hierarchical structure allows the subordinates to report to their superiors for any problem or issue in the daily operations and be informed of the actions to take to deal with it. In addition, a hierarchical structure is usually associated with more formalization and standardization so standard solutions can be obtained that take away the pressure and stress of uncertainty.

In contrast, in a culture featured with relatively lower power distance and lower uncertainty avoidance, members are more willing to take the challenge and risk of dealing with tough issues and appreciate more independent thinking and decision-making. A flat structure would workbetter since it provides an open internal arrangement that encourages decentralized decision-making and self-directing.

Overall, we suspect that organizational structural and national cultures jointly influence the effectiveness of different types of QM practices. Consequently, we conduct post-hoc analysis in this section. The two measurement items used in this study for organizational structure were adapted from existing literature (Aiken \& Hage, 1966; Burns \& Stalker, 1961; Zanzi, 1987). Respondents were asked to show the extent to which they agree with the following two statements about their plant on a seven-point Likert scale: (1) Many levels between the lowest level in the organization and top management, and (2) Organizational chart has many levels.

The two items had a positive and strong correlation (0.79). They wereaveraged to represent the construct of organizational structure. Based on the structure score, the sample is dividedinto twogroups. A higher average score implies a more hieratical structure, whereasa lower score indicates a flatter structure. The two cultural dimensions coupled with two organizational structure dimensions split the sample into four quadrats: Eastern+ Flat, Eastern+ Hieratical, Western+ Flat, and Western+ Hieratical. Within each group, the same regression analysis described in Section 4.1 was conducted to examine the potential different impacts from exploratory and exploitative QM practices on operations performance.The results are summarized in Table 5.

Table 5. Regression results in four groups

\begin{tabular}{lcccc}
\hline & $\begin{array}{c}\text { Eastern+ } \\
\text { Flat } \\
(\mathrm{n}=10)\end{array}$ & $\begin{array}{c}\text { Eastern+ } \\
\text { Hieratical } \\
(\mathrm{n}=56)\end{array}$ & $\begin{array}{c}\text { Western+ } \\
\text { Flat } \\
(\mathrm{n}=40)\end{array}$ & $\begin{array}{c}\text { Western+ } \\
\text { Hieratical } \\
(\mathrm{n}=43)\end{array}$ \\
\hline Industry $_{\text {Machinery }}$ & -0.46 & 0.01 & 0.26 & $0.55^{*}$ \\
Industry Electronics $_{\text {Quality }}$ & -0.51 & -0.07 & -0.03 & 0.06 \\
Quality & 0.61 & $0.43^{*}$ & -0.22 & 0.45 \\
R-Squation & 0.09 & -0.06 & $0.58^{*}$ & -0.06 \\
\hline$p$-value for the & 0.58 & 0.16 & 0.18 & 0.17 \\
\hline
\end{tabular}

Note: $* p<0.05$.

The group with Eastern national culture and flat organizational structure had a small sample size of 10 . Neither exploratory nor exploitative QM practices produced substantial impacts to overall operations performance. The group with Eastern national culture and hieratical structure had a sample size of 56 andexploitative QM practices generated significant positive effect to overall operations performance. For countries with western culture, the distribution between hierarchical structure and flat structure were quite even. Exploratory quality practices showed astronger influence to operations performance in the group featured with western national culture and flat organizational structure. Yet, in the quadrat of western culture and hierarchical structure, none of the effects from QM practices turned out to be significant. The overall results from the post-hoc analysis indicated that how effective the QM practices could be is dependent upon both national culture and organizational structure.

\section{Discussion and Implications}

More and more organizations try to implement quality management practices in order to gain competitive advantages and be more successful in market. However, past research does not show consistent results when investigating the influence of quality management practices on performance (Nair, 2006; Kaynak, 2003). National culture, as an important contextual factor, has drawn many scholars' attention. Scholars have debated whether QM should be treated as a universal set of practices and principles for a long time. Universal view means that QM practices and principles should be implemented without any difficulties across different cultural 
settings. However, many scholars concur the national specificity argument and state that differences in national cultural valuescouldset obstacles for the applicability of quality practices when they go across national boundaries (Goonatilake, 1998; Mersha, 1997; Noronha, 2002; Rungtusanatham et al., 1998; Rungtusanatham et al., 2005). For instance, Rungtusanatham et al. (2005) investigated the level of adoption of seven quality practices across five countries. Their results provided strong evidence for the argument that supports national specificity. This study adds another piece of evidence to support this argument by demonstrating the effectiveness of different $\mathrm{QM}$ practices varies across different culture groups.

Although recent studies (Kull \& Wacker, 2010; Naor et al., 2008) have suggested the influence of national culture on quality practices, the question of what kinds of QM practices are more effective within different culture profiles remainsunanswered. We, in this study, address this question by empirically assessing what types of QM practices work best under a specific culture setting. We find that two important national culturedimensions relevant to working environment promote the implementation ofonly a subset of QM practices, but not all of them. Within a national culture featured with high power distance and high uncertainty avoidance, exploitative QM practices contribute more to the performance than exploratory QM practices. In contrast, when the national culture has the features of low power distance and low uncertainty avoidance, exploratory QM practices work betterthan exploitative QM practices.

The findings also suggest that contingency perspective is a valuable approach to enrich our understanding of QM practices implementation. Figure 1 summarizes the implications from the post-hoc analysis. To achieve higher performance through QM practices, the internal organizational structure needs to fit the external cultural settings. For example, when operating in a culture dominated by high power distance and high uncertainty avoidance, a firm with a hierarchical structure would benefit more from exploitative QM practices.In contrast, when operating in a more western culture with a flat structure, firms may benefit more from exploratory QM practices.

\begin{tabular}{ll|l|r|}
\cline { 3 - 4 } \multicolumn{1}{c|}{ Eastern } & none & Exploitative practices \\
\cline { 3 - 4 } Culture group & & none \\
\cline { 3 - 4 } & \multirow{2}{*}{ Western } & Exploratory practices & Hieratical
\end{tabular}

Organizational structure

Figure 1. Effectiveness of different QM practices under the combination of national culture and organizational structure

Overall, the post-hoc analysis further indicates that choosing the right set of QM practices could be more complicated as the effectiveness of QM practices depends on the both internal factors (such as organizational structure) and external factors (such as national culture). In fact, each organization is unique in terms of these factors such as competitive environment, organizational structure, and organizational capability. As such, the notion of fit is crucial to best leverage QM practices to improve performance.A firm can benchmark others by introducing quality management into their system as a best practice, but it cannot exactly imitate what has been done in other firms. When the internal structure does not fit the national cultural settings, it would be hard to get the expected benefits from QM initiatives.

Last but not the least, the study offers insights into how to adapt quality management practices within different cultural settings and with different organizational structure. This could be crucial to firmswith offshore operations because it would not be easy for the management team (in home country) to understand aforeign culture and factor that into the decision of selecting the most appropriate set of QM practices in their offshore production sites. Rather, it is natural for them to extend what they have been using in domestic operations to foreign countries. The study suggests that if the domestic culture and foreign culture were close, this would not cause much problem. However, if the culture difference was dramatic, firms implementing some QM practices that do not fit with the foreign culture cannot garner the benefit they are supposed to get.

\section{Concluding Remarks}

National culture, as an important environmental factor, has drawn attention of many scholars (Zhao et al., 2007; Kull \& Wacker, 2010) when studying operations and supply chain issues. However, most cross-cultural studies tend to be descriptive and qualitative in nature.This studyconducts an empirical quantitative investigation of the 
effectiveness of different QM practices across different national culture groups in eight countries. Therefore, this research contributes to the qualityliterature from a cultural perspective. It supports the contingency view of QM effectiveness and provides a basis of guidance for practitioners to customize QM practices within different cultural profiles.

Furthermore, in an era of globalization, this study provides insight for practitioners in different nations. Resources are always limited for any organizations. Therefore, whether mangers could be able to allocateright resources to the right type of practices becomes crucial. By studying the quality practices with different orientations and clearly demonstrating which quality practices contribute more towards performance within different cultural settings, this study provides useful information to managers especially when multinational corporations invest overseas or cooperate with local supply chain partners. Understanding the local culture and adapting the QM practices that congruent with the culture would benefit the firms most.

There are a number of limitations to our study that can be addressed in future studies. The main purpose of this study is to examine the contingency effect from national culture on the linkage between QM practices and overall performance under Hofstede's national culture framework. Yet, we also extend the work to a more realistic circumstance where internal and external factor could work together to influence the effectiveness of exploitative and exploratory QM practices in the post-hoc analysis. Though the post-hoc analysis is insightful and the extension has much merit, the results need to be interpreted with caution. First of all, we only consider hierarchy as the measure for the organizational structure while neglect its other dimensions due to the dataset we have. Second, the group with Eastern culture and flat organizational structure has a small sample size, which makes the regression result less stable.Further analysis with enough data points is needed to verify the results. Third, though we found that quality management practices is more effective if there is a fit between organizational culture and national culture in the post-hoc analysis, more in-depth studies (such as case study) are highly needed to form a theoretical base to explain the interaction effect between them. It is hoped that by introducing national culture and organizational structure in the research on the effectiveness of different quality practices, this study sheds lights on the contingency view of quality management and provides a fruitful direction for future research.

\section{Reference}

Aiken, M., \& Hage, J. (1966). Organizational alienation: A comparative analysis. American Sociological Review, 497-507. http://dx.doi.org/10.2307/2090773

Bates, K. A., Amundson, S. D., Schroeder, R. G., \& Morris, W. T. (1995). The crucial interrelationship between manufacturing strategy and organizational culture. Management Science, 41(10), 1565-1580. http://dx.doi.org/10.1287/mnsc.41.10.1565

Blau, P. M. (1970). A formal theory of differentiation in organizations. American Sociological Review, 201-218. http://dx.doi.org/10.2307/2093199

Bright, K., \& Cooper, C. L. (1993). Organizational culture and the management of quality. Journal of Managerial Psychology, 8(6), 21-27. http://dx.doi.org/10.1108/02683949310047437

Burns, T., \& Stalker, G. M. (1961). The management of innovation. University of Illinois at Urbana-Champaign's Academy for Entrepreneurial Leadership Historical Research Reference in Entrepreneurship.

Cua, K. O., McKone, K. E., \& Schroeder, R. G. (2001). Relationship between implementation of TQM, JIT, and TPM and manufacturing performance. Journal of Operations Management, 19(6), 675-694. http://dx.doi.org/10.1016/S0272-6963(01)00066-3

Daft, R. L. (2009). Organization theory and design. South-Western Pub.

Dean, J. W. J., \& Bowen, D. E. (1994). Management theory and total quality: improving research and practice through theory development. Academy of Management Review, 19(3), 392-418.

Dow, D., Samson, D., \& Ford, S. (1999). Exploring the myth: Do all quality management practices contribute to superior quality performance? Production and Operations Management, 8(1), 1-27. http://dx.doi.org/10.1111/j.1937-5956.1999.tb00058.x

Flynn, B. B., \& Saladin, B. (2006). Relevance of Baldrige constructs in an international context: a study of national culture. Journal of Operations Management, 24(5), 583-603. http://dx.doi.org/10.1016/j.jom.2005.09.002

Flynn, B. B., Schroeder, R., \& Sakakibara, S. (1995). The impact of quality management practices on 
performance and competitive advantage. Decision Sciences, 26(5), 659-692. http://dx.doi.org/10.1111/j.1540-5915.1995.tb01445.x

Foster, S. T. (2006). One Size Does Not Fit All. Quality Progress, 39(7), 54-61.

Germain, R., Claycomb, C., \& Dröge, C. (2008). Supply chain variability, organizational structure, and performance: the moderating effect of demand unpredictability. Journal of Operations Management, 26(5), 557-570. http://dx.doi.org/10.1016/j.jom.2007.10.002

Goonatilake, L. (1998). Evaluation of quality management constrains in developing countries. Industrial Management and Data Systems, 88(7/8), 6-10. http://dx.doi.org/10.1108/eb057514

Hofstede, G. (1980). Motivation, leadership and organizations: do American theories apply abroad? Organizational Dynamics, 9(1), 42-63. http://dx.doi.org/10.1016/0090-2616(80)90013-3

Hofstede, G. (1994a). Management scientists are human. Management Science, 40(1), 4-13. http://dx.doi.org/10.1287/mnsc.40.1.4

Hofstede, G. (1994b). Cultural constraints in management theories. International Review of Strategic Management, 5, 27-48.

Hofstede, G. (1997). Cultures and Organizations: Software of the Mind: Intercultural Cooperation and its Importance for Survival. New York, NY: McGraw-Hill.

House, R. J., Hanges, P. J., Javidan, M., Dorfman, P. W., \& Gupta, V. (2004). Culture, leadership, and organizations. Sage.

Kull, T. J., \& Wacker, J. G. (2010). Quality management effectiveness in Asia: The influence of culture. Journal of Operations Management, 28(3), 223-239. http://dx.doi.org/10.1016/j.jom.2009.11.003

Lagrosen, S. (2003). Exploring the impact of culture on quality management. International Journal of Quality \& Reliability Management, 20(4/5), 473-487. http://dx.doi.org/10.1108/02656710310468632

Lozeau, D., Langley, A., \& Denis, J. L. (2002). The corruption of managerial techniques by organizations. Human Relations, 55(5), 537-564. http://dx.doi.org/10.1177/0018726702055005427

Lytle, A. L., Brett, J. M., Barsness, Z. I., tinsley, C. H., \& Janssens, M. (1995). A paradigm for confirmatory cross-cultural research in organizational behavior. In L. L. Cummings \& B. M. Staw (Eds.), Research in Organizational Behavior (Vol. 17, pp. 167-194).

March, J. G. (1991). Exploration and exploitation in organizational learning. Organization Science, 2(1), 71-87. http://dx.doi.org/10.1287/orsc.2.1.71

Mersha, T. (1997). TQM implementation in LDCs: driving and restraining forces. International Journal of Operations and Production Management, 17(2), 164-183. http://dx.doi.org/10.1108/01443579710158032

Naor, M., Goldstein, S. M., Linderman, K. W., \& Schroeder, R. G. (2008). The role of culture as driver of quality management and performance: Infrastructure versus core quality practices. Decision Sciences, 39(4), 471-702. http://dx.doi.org/10.1111/j.1540-5915.2008.00208.x

Narasimhan, R., Swink, M., \& Kim, S. W. (2006). Disentangling leanness and agility: An empirical investigation. Journal of Operations Management, 24(5), 440-457. http://dx.doi.org/10.1016/j.jom.2005.11.011

Noronha, C. (2002). Culture-specific TQM in China: Case Studies for Theoretical Consideration. Asian Business \& Management, 1(1), 125-145. http://dx.doi.org/10.1057/palgrave.abm.9200008

Peng, D. X., \& Shah, R. (2008). Linking routines to operations capabilities: A new perspective. Journal of Operations Management, 26(6), 730-748. http://dx.doi.org/10.1016/j.jom.2007.11.001

Powell, T. C. (1995). Total quality management as competitive advantage: A review and empirical study. Strategic Management Journal, 16(1), 15-37. http://dx.doi.org/10.1002/smj.4250160105

Rungtusanatham, M., Forza, C., Filippini, R., \& Anderson, J. C. (1998). A replication study of a theory of quality management underlying the Deming management method: insights from an Italian context. Journal of Operations Management, 17(1), 77-95. http://dx.doi.org/10.1016/S0272-6963(98)00032-1

Rungtusanatham, M., Forza, C., Koka, B. R., Salvador, F., \& Nie, W. (2005). TQM across multiple countries: Convergence hypothesis versus national specificity arguments. Journal of Operations Management, 23(1), 43-63. http://dx.doi.org/10.1016/j.jom.2004.10.002 
Schroeder, R. G., Bates, K. A., \& Junttila, M. A. (2002). A resource-based view of manufacturing strategy and the relationship to manufacturing performance. Strategic Management Journal, 23(2), 105-117. http://dx.doi.org/10.1016/j.jom.2004.10.002

Sitkin, S. B., Sutcliffe, K. M., \& Schroeder, R. G. (1994). Distinguishing control from learning in total quality management: a contingency perspective. Academy of Management Review, 19(3), 537-564.

Sousa, R., \& Voss, C. A. (2008). Contingency research in operations management practices. Journal of Operations Management, 26(6), 697-713. http://dx.doi.org/10.1016/j.jom.2008.06.001

Tata, J., \& Prasad, S. (1998). Cultural and structural constrains on total quality management implementation. Total Quality Management, 9(8), 703-710. http://dx.doi.org/10.1080/0954412988172

Triandis, H. C. (1983). Dimensions of cultural variations as parameters of organizational theories. International Studies of Management and Organization, 12(4), 139-169.

Wu, J., Zhang, D., \& Schroeder, R. (2011). Customization of Quality Practices: The Impact of Quality Culture. International Journal of Quality and Reliability Management, 28(3), 263-279. http://dx.doi.org/10.1108/02656711111109883

Zanzi, A. (1987). How organic is your organization?-determinants of organic/mechanistic tendencies in a public accounting firm. . Journal of Management Studies 24(2), 125-140. http://dx.doi.org/10.1111/j.1467-6486.1987.tb00940.x

Zhang, D., Linderman, K., \& Schroeder, G. (2012). The Moderating Role of Contextual Factors on Quality Management Practices. Journal of Operations Management, 30(1), 12-23. http://dx.doi.org/10.1016/j.jom.2011.05.001

Zhao, X., Flynn, B., \& Roth, A. (2007). Decision Sciences research in China: Current status, opportunities, and propositions for research in supply chain management, logistics, and quality management. Decision Sciences, 38(1), 39-80. http://dx.doi.org/10.1111/j.1540-5915.2007.00148.x

\section{Appendix}

Measurement of Exploitative and Exploratory Quality Practices

Respondents need toanswerthe following questions and show the extent to which they agree with each of these statements about their plant and organization (1: Strongly disagree, 4: Neutral, 7: Strongly agree)

\begin{tabular}{|c|c|c|}
\hline & Exploitative & Exploratory \\
\hline $\begin{array}{l}\text { Customer } \\
\text { focus }\end{array}$ & $\begin{array}{l}\text { - We frequently are in close contact with our } \\
\text { customers } \\
\text { - Our customers give us feedback on our quality } \\
\text { and delivery performance } \\
\text { - We regularly survey our customers' needs. }\end{array}$ & $\begin{array}{l}\text { - We consulted customers early in the design efforts } \\
\text { for this product. } \\
\text { product } \\
\text { - Customers were frequently consulted about the design } \\
\text { of this product. } \\
\text { - Customers were an integral part of the design effort } \\
\text { for this project. }\end{array}$ \\
\hline $\begin{array}{l}\text { Process } \\
\text { management }\end{array}$ & $\begin{array}{l}\text { - We make extensive use of statistical techniques to } \\
\text { reduce variance in processes. } \\
\text { - We use charts to determine whether our } \\
\text { manufacturing processes are in control. } \\
\text { - We monitor our processes using statistical process } \\
\text { control. }\end{array}$ & $\begin{array}{l}\text { - We strive to continually improve all aspects of } \\
\text { products and processes, rather than taking a static } \\
\text { approach. } \\
\text { - Improvement of a process is never complete; there is } \\
\text { always room for more incremental improvement. } \\
\text { - Our organization is not a static entity, but engages in } \\
\text { dynamically changing itself to better serve its } \\
\text { customers. }\end{array}$ \\
\hline Teamwork & - Our supervisors encourage the people who work & - The functions in our plant cooperate to solve conflicts \\
\hline
\end{tabular}




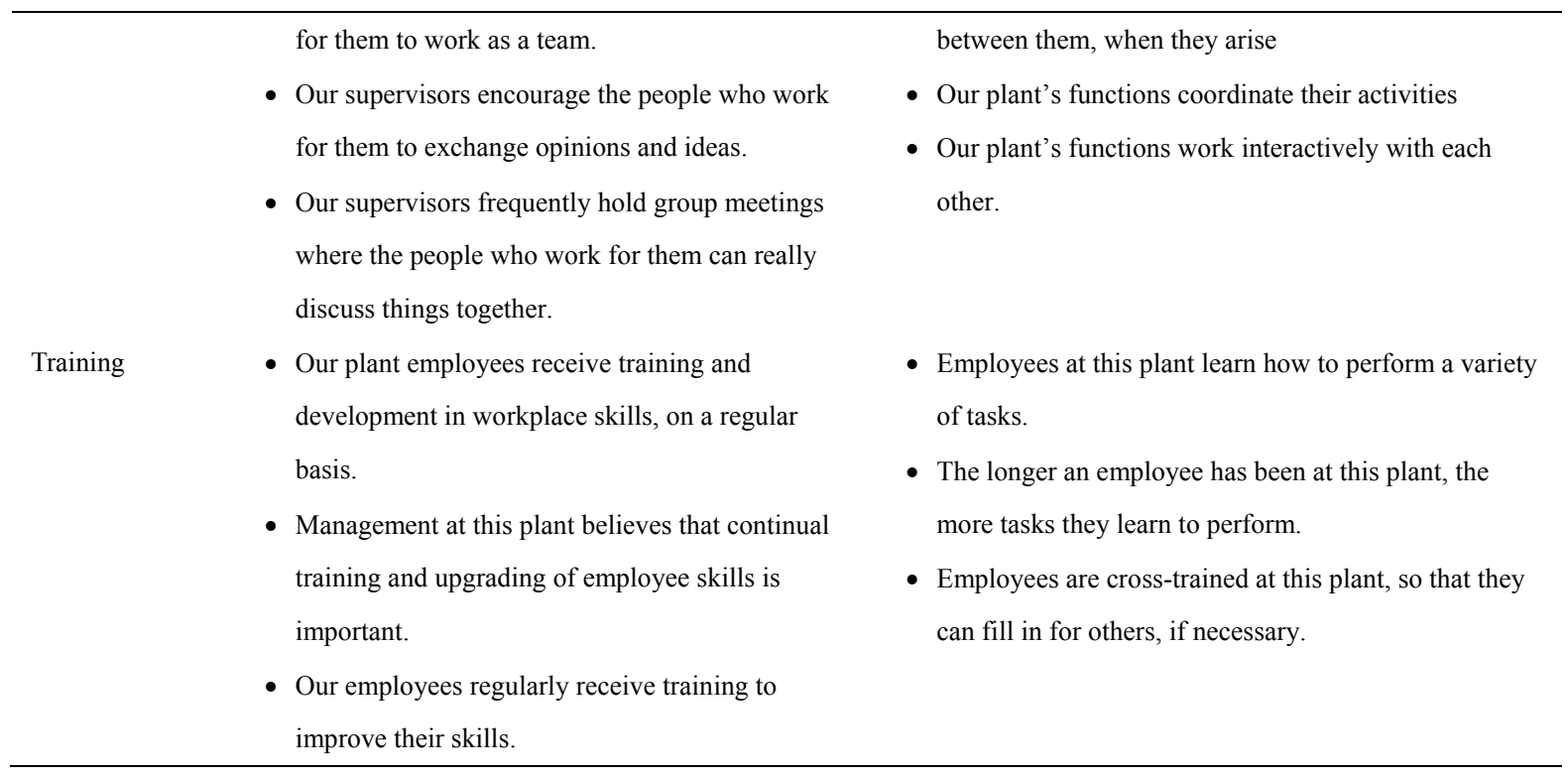

Source: Zhang, D., Linderman, K., \& Schroeder, G. (2012). The Moderating Role of Contextual Factors on Quality Management Practices. Journal of Operations Management, 30(1), 12-23.

\section{Copyrights}

Copyright for this article is retained by the author(s), with first publication rights granted to the journal.

This is an open-access article distributed under the terms and conditions of the Creative Commons Attribution license (http://creativecommons.org/licenses/by/3.0/). 